\title{
A improvisação musical e a tradição escrita no Ocidente
}

\author{
Sonia Albano de Lima, Cesar Albino* \\ Instituto de Artes da UNESP
}

\section{Resumo:}

O artigo descreve a trajetória da improvisação musica no Ocidente, desde a tradição oral até a tradição escrita. A partir da conceituação do termo, os autores expõem os momentos mais relevantes dessa prática no universo da música erudita. A fundamentação teórica está focada em diversos autores: Dereck Bailey. Stephen Nachmanovitch, Fernando Oliveira Rocha, Manoel Carlos Pego Saisse, Allen Brings e outros. Admite-se que embora a improvisação permeie boa parte dessa história, incentivando novas estruturas notacionais, novos estilos e novas performances, ela deixa de existir a partir de sua transcrição, levando em conta a sua natureza eminentemente praxiológica. Mesmo assim, os autores consideram importante que ela seja adotada no ensino musical, uma vez que possibilita ao músico erudito maior destreza performática e melhor criatividade interpretativa. O texto aqui articulado integra parte da dissertação de mestrado que está sendo desenvolvida no IA-UNESP.

Palavras-chave: improvisação; tradição escrita; música erudita ocidental

*Sonia Albano de Lima é Doutora em Comunicação e Semiótica (PUC-SP) e Pós-Doutora em Educação (GEPI-PUC-SP). Especialista em Interpretação Musical e Música de Câmara (FMCG). Bacharel em Direito (USP). Diretora e coordenadora pedagógica dos Cursos de Graduação e Pós-Graduação da FMCG. Professora do Mestrado e Doutorado em Música do IA-UNESP. É pesquisadora do GEPI-PUC/SP. Possui várias publicações em anais nacionais e internacionais, revistas, além de livros e coletâneas.

* César Albino é bacharel em saxofone e licenciado em Música (FMCG). Estudou saxofone com Roberto Sion, José Carlos Prandini e Eduardo Pecci no CMBP e CLAM. Possui pósgraduação lato sensu em educação musical, área de concentração - Práticas pedagógicas (FMCG). Leciona improvisação, instrumento e prática de conjunto nos cursos de bacharelado em música popular da FMCG. É professor É mestrando em música pelo IAUNESP. Autor dos métodos de saxofone (2003) e flauta transversal (2005) pela editora Gondine. 
A improvisação musical no Dicionário Grove de Música foi definida como a criação de uma obra musical, ou de sua forma final, à medida que está sendo executada. Pode significar a composição imediata da obra pelos executantes, a elaboração ou ajustes de detalhes numa obra já existente, ou qualquer coisa dentro desses limites (1995, p. 450). Neste contexto, criar uma obra ou ornamentar uma peça instantaneamente pode ser entendido como improvisação. Stephen Nachmanovitch assim se refere ao termo:

$\mathrm{Na}$ improvisação, há apenas um momento. A inspiração, a estruturação e a criação da música, a execução e a exibição perante uma platéia ocorrem simultaneamente num único momento em que se fundem memória e intenção (que significam passado e futuro) e intuição (que indica o eterno presente). O ferro está sempre em brasa (1993, p. 28).

Violeta Gainza vê dois momentos importantes na improvisação. Um expressivo, em que o intérprete, independente do resultado, esforça-se para expressar e exteriorizar o que está internalizado; e outro momento introspectivo, que se dá por meio da investigação, da exploração, do exercício em que aquele intérprete manipula os objetos sonoros e extra-sonoros com o intuito de absorvêlos em pura pesquisa sonora (1983 p. 23-25).

Os músicos, até o advento da gravação, sempre tiveram de lidar com a frustração de não poder registrar esse momento único, que emerge de dentro e quer saltar para fora, expressar-se, tomar vida. Derek Bailey, no livro Improvisation: its nature and practice in music (1993) fala das dificuldades em se promover uma abordagem histórica da improvisação, devido à natureza nãodocumental da atividade. Nessa publicação, ele se reporta ao musicólogo Ernest Ferand, que demonstrou a intensa presença dessa atividade em toda a história da música, mesmo em uma área tão inóspita a tal atividade como foi o Ocidente no início do século XX (Bailey, 1992, p. 9): 
Essa alegria de improvisar enquanto se canta e se toca um instrumento é evidente em quase todas as fases da história da música. Essa foi sempre uma força poderosa na criação de novas formas, e todo o estudo histórico que se limita à prática ou às fontes teóricas que nos foram deixadas de forma escrita ou impressa, sem levar em conta o elemento de improvisação e a vivência da prática musical, deve ser considerado necessariamente como algo incompleto, certamente um retrato distorcido. Pois quase não há um único campo na música que não tenha sido afetado pela improvisação, nem uma única técnica musical ou forma de composição que não tenha tido origem na prática improvisadora, nem que nạo tenha sido influenciado essencialmente por ela. Toda a história do desenvolvimento da música é acompanhada por manifestações de impulsos para se improvisar. (Ferand, 1961 apud Bailey, 1992, p. ix e x, tradução nossa).

Keith Jarrett, no prefácio da transcrição do Köln Concert realizada por Yukiko Kishinami e Kunihiko Yamashita (Schott, 1991), a partir da gravação do concerto realizado em 24 de janeiro de 1975 pela gravadora ECM, diz que relutou muito em aceitar a transcrição dessa obra pelos seguintes motivos: Primeiramente, esse foi um concerto totalmente improvisado e estava destinado a desaparecer tão rapidamente quanto havia surgido, pois essa é a natureza da improvisação. Depois, porque muitos dos trechos da gravação seriam impossiveis de serem transcritos em um sistema de notação tradicional como o nosso. Para ele, essa transcrição deve ser entendida como "uma aproximação" daquela música que foi tocada e gravada. Ele só permitiu a transcrição desse concerto mediante a sua supervisão. Em algumas passagens da transcrição as notas estão corretas; mas devido à constante flutuação do tempo na obra executada, foi impossível adotar uma notação métrica precisa. Também foi necessário se contentar com alguns erros de escrita, provenientes da adoção de um sistema de notação tradicional, às vezes inadequado para a transcrição:

Em algumas partes nós tivemos que nos contentar com algumas imprecisões de escrita, pois uma notação precisa contrariaria o sentido da obra, já que nenhum dos métodos de notação conhecidos eram adequados para transcrever algumas partes da obra. [...]Por exemplo, nas páginas 50 e 51 da segunda parte da peça, é quase impossível transcrever o ritmo real desta passagem. Ele é muito mais real na gravação do que nas notas que foram impressas. Muitas delas foram selecionadas a partir de um sentido rítmico; outras dependeram da harmonia ou do tratamento da nota (ou das notas) precedente(s). Se tivéssemos transcrito todas as notas, teríamos uma escuta irreal da obra. Foi importante selecionar algumas notas. Mesmo esta seleção não conferiu à transcrição o verdadeiro sentido desta passagem. Como na improvisação, é a audição do trecho que determinará a força da música. (Jarret, 1991. Prefácio, tradução nossa). 
Para Jarrett essa transcrição configura-se como um documento da obra improvisada para que musicólogos e compositores possam analisá-la posteriormente. Ela não é uma reprodução fiel da execução. Os pianistas devem ter nessa partitura apenas um referencial e nada mais.

Tomando como exemplo a Europa da Idade Média, vamos observar que o sistema de notação musical, ainda rudimentar tanto para as alturas quanto para as durações, permitiu que alguns componentes da música fossem alterados, recombinados e finalmente memorizados na forma final da idéia musical. Nesse período as atividades de compor, executar e improvisar fundiam-se na mesma pessoa; a improvisação foi um recurso bastante utilizado.

Com o aprimoramento do sistema notacional, essas práticas puderam ser transcritas. Em razão disso, a improvisação foi perdendo espaço, pois a busca por uma grafia musical condizente fez cair a utilização da improvisação nos processos de execução. Houve a necessidade, então, de se fixar por escrito estruturas musicais por meio de signos: "Avançava-se por tanto também até uma codificação escrita que se distanciava da tradição oral e da improvisação." (Martin, 2001, s.p., tradução nossa).

Diversos autores admitem que a improvisação começa a desaparecer no Ocidente à medida que o sistema de notação se desenvolve (lazzetta, 2001: Martin, 2001; Nachmanovitch, 1993; Rocha, 2001). Mesmo assim, no período barroco, apesar de o sistema notacional já estar praticamente consolidado, a improvisação ainda foi muito utilizada. Havia a clara intenção de improvisar em música, talvez por força de uma tradição oral que fazia parte do cotidiano musical.

J. S. Bach, por exemplo, na sua época, foi mais conhecido como um exímio improvisador do que como compositor, apesar do fato de que foram as suas partituras que nos permitiram conhecer a sua música. Das suas improvisações restam apenas depoimentos de seus contemporâneos que puderam testemunhar essa sua habilidade. James Galway, ao narrar o valor que a música teve nas gerações passadas, descreve a habilidade de improvisar desse grande mestre: 


\begin{abstract}
A música tinha um valor muito mais efêmero para as gerações passadas; regra geral, não se pensava que fosse importante preservar as obras musicais para a posteridade, pois uma vez executadas, elas teriam cumprido sua missão e seriam substituídas por música mais recente (supostamente melhor). O grande respeito pela música do passado é, em larga medida, um fenômeno do século XX. É provável que algumas das mais belas obras de Bach não tenham sequer sido escritas - seus contemporâneos consideravamno insuperável como improvisador no teclado, tocando excelente música de improviso, sem qualquer preparação. Dizia-se que se Bach entrasse numa igreja quando o organista estivesse tocando o tema de uma fuga improvisada, era capaz de dizer instantaneamente quais os artifícios da técnica de fuga que podiam ou não ser aplicados ao tema e ficava maliciosamente deleitado se o executante ignorava o que era possível como quando ele tentava o impossível e falhava. (Galway, 1987, p. 77).
\end{abstract}

Boa parte da improvisação no Barroco esteve contida no baixo figurado (baixo contínuo) ${ }^{1}$ - um sistema de escrita musical que registra certos elementos relativos à harmonia da música. Consiste em uma linha de baixo escrita de forma convencional a ser executada comumente pelo cravo e o violoncelo, embora também pudesse ser executado pelo órgão, a viola da gamba ou o fagote. 0 músico encarregado de executar o instrumento de teclado deveria tocar esse baixo com a mão esquerda e improvisar com a mão direita a harmonia indicada pelas figuras (números) sob a linha do baixo. Geralmente, esse executante era o que dirigia o grupo e o compositor da obra (Brings et alius 1979, p. 77; Galway, 1987, p. 83).

O baixo figurado deixou de ser empregado pelos compositores pósbarrocos, mas ainda é tradição para os intérpretes contemporâneos especializados em música barroca. ${ }^{2} \mathrm{Na}$ música barroca havia ainda outros espaços onde se

\footnotetext{
1 Expressão que se refere à parte ininterrupta de baixo que percorre toda a obra concertante do período barroco (também do Renascimento tardio e do primeiro período clássico) e serve como base para as harmonias. As partes para contínuo podem ser cifradas para indicar ao executante quais harmonias podem ser adequadamente acrescentadas. A prática da execução do contínuo surgiu numa época em que a música estava sendo cada vez mais concebida em termos de progressão harmônica, com uma linha ou linhas melódicas sublinhadas por uma linha de baixo e as harmonias de apoio (Sadie, 1994, p. 66).

${ }^{2}$ Não é inusitado nos dias atuais assistirmos a um concerto de música barroca onde o cravista improvisa como se fazia naquele período histórico. Na Europa, principalmente na França, é possível ouvir organistas improvisando do mesmo modo como faziam os organistas do tempo de Bach (Bailey, 1992, p. 37).
} 
esperava que o intérprete executasse mais do que aquilo que estava escrito. Essas situações aconteciam nas repetições, sempre propícias à improvisação:

Em muitas composições, a linha melódica não era escrita por extenso. Esse trabalho cabia ao intérprete, que tomando como base pontos essenciais fixados na partitura, executava a melodia empregando diminuições e outras ornamentações. Vivaldi fornece exemplos do caráter esquemático em que eram notadas suas composições instrumentais. O exame de alguns movimentos lentos da época demonstra que muitos deles estavam esboçados em notas de valores longos, exigindo uma complementarização do intérprete durante a execução. Haendel, na segunda edição da Suíte em ré menor para cravo, escreveu por extenso a ornamentação da melodia, o que não fizera na primeira tiragem que estava apenas reduzida às notas essenciais (Couto e Silva, 1960, apud Lima, 2006, p. 53).

É fácil deduzir que tais técnicas funcionavam em formaçōes camerísticas pequenas, executadas ora por um solista, ora por outro, seja na voz ou no instrumento. Mas no período clássico, nas formações mais densas, a prática improvisatória passou a ter uma aplicabilidade bem mais restrita, até porque tal grupo exigia a presença de um regente, o que antes era realizado pelo próprio executante do baixo contínuo. Contudo, na cadenza dos concertos permitia-se a improvisação, principalmente nas obras de Haendel e Corelli. O violinista Yehudi Menuhin admite que essa prática estendeu-se para o solista virtuose. Mozart foi um dos primeiros compositores que permitiu nas cadências de concertos que o solista improvisasse sobre temas e figurações contidos no movimento que estava sendo executado (Menuhin \& Davis, 1979, p. 164). Entretanto, não demorou muito para que os futuros compositores passassem a escrever suas próprias cadenzas, principalmente quando perceberam nos executantes certo declínio na capacidade de improvisar. Beethoven foi o primeiro a fazer isso no Concerto para piano forte n. 5, em mi bemol maior, op. 73 (1809) - o Imperador.

Gradualmente, os compositores foram adotando uma escrita musical extremamente precisa, abolindo qualquer espaço para a improvisação. Tal procedimento seguiu até o serialismo integral no século XX.

Tanto é seguro afirmarmos que a improvisação desapareceu da música clássica ocidental devido ao aprimoramento do sistema notacional, como 
também, pelo prestígio e influência que os regentes passaram a ter na condução das orquestras: "A limitação gradual e a eliminação final da improvisação nessa música também parece ter ocorrido no mesmo período que presenciou o crescente predomínio do regente de orquestra, o representante do compositor" (Bailey, 1993, p. 20). Não obstante, a separação gradual que se estabeleceu entre a figura do compositor e do intérprete também contribuiu para o declínio das atividades improvisatórias. Atividades que no passado eram exercidas por um único músico passam a ser desmembradas:

A Era industrial trouxe consigo uma valorização excessiva da especialização e do profissionalismo em todos os campos de atividade. Os músicos, em sua grande maioria, viram-se restringidos a executar nota por nota as partituras escritas por um grupo de compositores que de alguma forma tinham acesso ao divino e misterioso processo de criação. A composição e a execução foram se separando gradualmente, em prejuízo de ambas. Formas clássicas e populares também foram se afastando cada vez mais, novamente em prejuízo de ambas. $O$ novo e o velho perderam continuidade (Nachmanovitch, 1993, p. 20).

Dessa forma, ao compositor restou compor e ao intérprete executar aquilo que estava escrito na partitura. E nessa nova configuração, nem os

102 compositores disponibilizavam espaço para a improvisação, nem executantes se acomodavam com tal determinação.

Com o advento do lluminismo predominou entre os teóricos e compositores a certeza de que faltava ao músico a racionalidade e a cientificidade presentes nas demais áreas de conhecimento. Essa determinante fez surgir cada vez mais na história da música ocidental a sacralização da partitura:

Mais e mais, no iluminismo, os intérpretes pautaram suas execuções na fidelidade à partitura, no cumprimento eficaz dos modelos interpretativos sugeridos pelos teóricos e musicólogos, uma vez que essa atitude conferia ao discurso musical maior cientificidade. A partitura, vista como recriação fidedigna da composição musical, firmou-se como modelo inquestionável de perfeita execução (Lima, 2006, p. 57). 
Este padrão epistemológico propiciou o abandono das práticas improvisatórias nos processos interpretativos. A improvisação consumou-se como uma atividade de somenos importância, até mesmo perniciosa para o intérprete:

$\mathrm{Na}$ tradição musical escrita observamos ainda o nascimento de um intérprete musical cada vez mais subjugado à partitura, afastado da prática improvisatória e da liberdade de expressão, costumes bastante freqüentes na tradição oral. Mesmo assim, os novos referenciais não foram capazes de excluir a cumplicidade participativa do intérprete no ato da execução e muito menos afastar as alterações performáticas oriundas de fatores histórico-culturais introduzidos na sociedade (Lima, 2005, p. 20).

O desenvolvimento da tradição escrita no Ocidente foi capaz de perpetuar a idéia musical manifestada pelo compositor e ampliar a sua reprodução no tempo e no espaço; entretanto, promoveu o declínio da prática improvisatória nos processos de execução. Manoel Carlos P. Saisse, em artigo publicado na Revista Música Hoje (199-?), analisa sob uma perspectiva histórica a relação existente entre tecnologia e música, focando não só a utilização dos instrumentos eletrônicos por parte do compositor para a produção da obra musical, como também, o controle que ele detém na transmissão de suas idéias musicais na partitura, inibindo a liberdade interpretativa do executante.

Saisse esclarece que no final do século XVIII e ao longo do século XIX, a busca por uma notação musical precisa foi significativa. As convenções de execução anteriores, que davam ao intérprete uma razoável flexibilidade em relação às indicações fornecidas, deram lugar a uma segunda ordem - o intérprete deveria ser fiel à notação musical expressa na partitura. Dessa forma, podemos intuir que os sistemas de notação no Ocidente evoluíram no sentido de expandir cada vez mais a área de controle do compositor sobre a execução musical, em detrimento da liberdade interpretativa do executante sobre a partitura. A tendência de expansão dessa área de controle do compositor pode ser observada com bastante clareza na produção musical do início do século XX. Inicialmente esses meios eletrônicos de produção de som foram utilizados pelos 
compositores, de forma a ampliar a área de controle sobre a execução musical - só mais tarde foram empregados como meio efetivo de produção sonora (Saisse, 199-?)

Essa realidade histórica traz consigo uma realidade contraposta: como explicar, à luz desta tendência tão restritiva, o surgimento da música chamada aleatória, da qual Cage foi o grande representante?

Neste período assistimos a uma expansão da área de indeterminação nas composições e uma liberdade interpretativa a níveis jamais vistos na história da música ocidental, despojando muitas vezes a composição de qualquer vestígio de controle advindo do compositor. Também nesse período, os meios tecnológicos que haviam sido empregados como proibitivos da liberdade interpretativa foram utilizados como ferramentas adicionais para a produção sonora.

Para Saisse, essas duas tendências antagônicas levaram o compositor a reavaliar a função do intérprete e do acaso na execução musical e perceber que a tecnologia trouxe para o compositor a possibilidade de determinar os limites de sua área de controle, a área de controle do intérprete e a área de indeterminação que poderiam estar presentes na partitura:

Até então, toda a parte da execução musical que não correspondesse à intenção do intérprete ou do compositor em qualquer obra musical era vista como erro que deveria, sumariamente, ser eliminado e evitado. A partir do instante em que existe a possibilidade de se eliminar quase que totalmente o erro, o compositor passa a poder utilizar intencionalmente o acaso em suas composições. Seqüências de sons e silêncios gerados aleatoriamente ganham uma função estética na música moderna e podem ser encarados não mais como decorrência de uma limitação intrínseca do processo de produção musical (pois a tecnologia eletrônica desenvolveu meios de produção de som que permitiram reduzir a níveis mínimos esta restrição) mas sim como resultado de uma atitude intencional do compositor. O mesmo raciocínio é válido no que diz respeito à posição do intérprete na execução musical, ou seja, uma área de controle do intérprete pode ser intencionalmente reservada e delimitada pelo compositor numa obra musical. Talvez a grande inovação trazida pela tecnologia eletrônica para a música ocidental tenha sido não a possibilidade oferecida ao compositor de exercer um amplo controle sobre a execuccão de suas obras, mas sim, a possibilidade de determinar com uma grande flexibilidade, os limites de sua área de controle, bem como da área de controle do intérprete e da área de indeterminação. (p. 55). 
O serialismo integral, onde o princípio serial de organização dos sons não se dá apenas nas alturas, mas também nas durações, ataques e dinâmicas, proporcionou um controle quase que absoluto, até doutrinário do compositor sobre sua obra. Coincidentemente é nessa época que a música eletrônica também se desenvolve na Europa, podendo inclusive adotar o serialismo, dentre outras práticas composicionais. Na música eletrônica, o compositor podia trabalhar seu material diretamente, podendo ouvi-lo em seguida, sem necessitar de um intérprete. Esse comportamento cria um canal direto de comunicação entre o compositor e sua obra. Griffths cita como exemplo as composições de Edgar Varèse e Pierre Schaeffer (1987, p. 146).

Ao mesmo tempo, surge nos EUA uma outra corrente, incorporando o aleatório, a indeterminação e a improvisação na música erudita. Como exemplo dessa nova prática, temos as obras de John Cage e Earle Brown (Rocha, 2001, p. 5). A partitura 4'33" escrita por Cage, em 1952, leva ao extremo o conceito de acaso e indeterminação. Não há na obra uma única nota escrita, apenas a indicação tacet (não toque) e o tempo que isso deve durar (4 minutos e trinta e três segundos).

Vários motivos determinaram essa nova forma de compor: motivos filosóficos, de criação gráfico-musical, de representação sonora, estéticos, históricos e culturais. Certos compositores detectaram que o sistema notacional tradicional já não atendia mais às necessidades composicionais. Efeitos extraídos com muita dificuldade das partituras do serialismo integral podiam ser obtidos de uma forma mais interessante e espontânea utilizando-se a indeterminação. $\mathrm{Na}$ peça Music for cello and piano de Earle Brown, composta em 1955, o compositor utiliza um sistema particular de notação rítmica, não mecânico, onde a duração é espacializada na partitura e sua interpretação se dá por aproximação visual: 


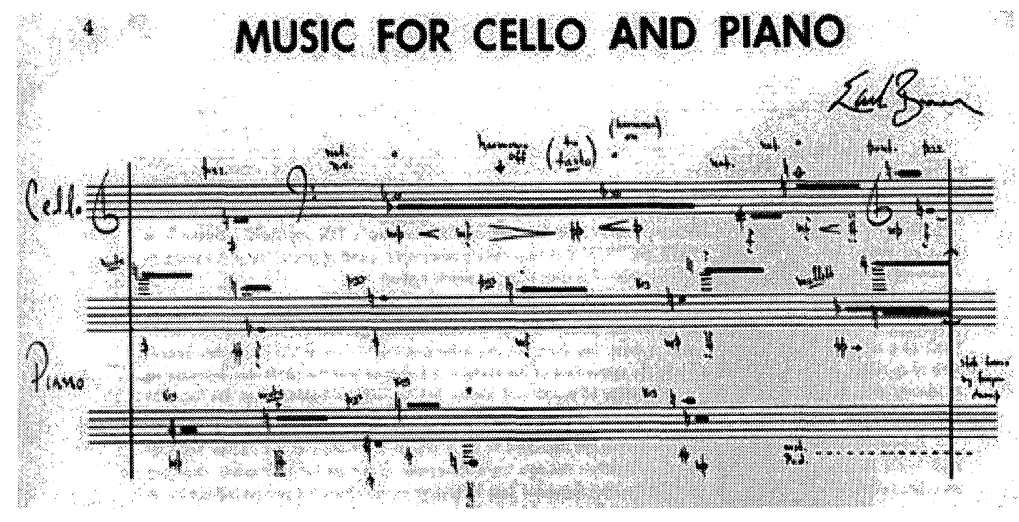

Muitas das partituras gráficas nasceram da intenção dos compositores em criar um sistema notacional apropriado às novas idéias. Em algumas dessas obras concentravam-se em igual medida, a fidelidade às idéias do compositor e uma liberdade interpretativa até então não reconhecida nas partituras que seguiam a notação tradicional. Xenakis na obra Psappha para percussão, ao adotar outro sistema baseado no grafismo, consegue um grau ainda mais alto de precisão do que a notação tradicional.

No mesmo período, observa-se também a implantação da 106 indeterminação proposital. Para obter tal resultado, alguns compositores utilizavam o aleatório ou a improvisação (Griffiths, 1987, p. 159-160). Nessas duas possibilidades o compositor abdica da tomada de decisão, só que na aleatoriedade a decisão fica por conta do acaso - o produto final, ou parte dele, não pode ser previsto (Cope apud Rocha, 2001, p. 16). A composição Twenty Five Pages (1953) de Earle Brown, para 1 ou até 25 pianos, onde a ordenação das 25 páginas da música fica a critério do(s) intérprete(s) e o Musikalisches Würfelspiel (Jogo de Dados) de W.A. Mozart (1777) são exemplos do emprego de elementos aleatórios na composição. Na obra de Mozart, por exemplo, a ordem dos compassos deve ser escolhida a partir da emissão de dois dados.

Já na improvisação, a tomada de decisão fica a cargo do intérprete (Bailey, 1992, p.60). Alguns compositores não só aceitaram as práticas improvisatórias como também incentivaram a espontaneidade do intérprete. 
Como exemplo, temos a obra Stop (1965) de Stockhausen, e a série de concertos improvisados do pianista americano Keith Jarrett, que durante as décadas de 1970-80 realizou uma série de concertos em várias cidades do mundo, inclusive São Paulo, tocando músicas compostas no momento de sua execução - uma autêntica improvisação. Vários desses concertos foram gravados pela ECM Records, como o Köln Concert (1975) e Vienna Concert (1992).

A utilização da improvisação pelos compositores eruditos teve seu auge até as décadas de 60/70; posteriormente, essa prática composicional foi decaindo e os intérpretes continuaram a seguir as indicações da partitura de forma irrestrita. Diversas são as razões, dentre elas destacamos: a forte tradição escrita do repertório erudito; o número restrito de composições destinadas a essa prática; a maior utilização da improvisação pelo músico popular; a falta do ensino da improvisação nos cursos técnicos e superiores de música erudita.

A improvisação tem sido utilizada pelos educadores musicais, nos cursos de musicalização e de iniciação musical, com o intuito de incentivar a criatividade; ela também é empregada no estudo das escalas, nos exercícios de técnica, na memorização de jargões melódicos e harmônicos de difícil execução, tornando o estudo performático não tão repetitivo e enfadonho. Os organistas também estão utilizando a improvisação tanto como imitação estilística, como nos motivos litúrgicos e de criação. No culto luterano, por exemplo, é imprescindível saber improvisar. Para isso é necessário que o organista tenha um bom desempenho técnico, certo domínio harmônico-melódico, um trabalho preliminar de percepção musical e uma boa vivência do repertório musical. Para Lima (2006) a improvisação adquiriu na música erudita uma nova função performática:

Essa tarefa (de interpretar), entretanto, não afastou o executante de um sentido improvisatório que está na função de se expressar e expressar a inteireza da obra musical de forma criativa. Improvisar, na atualidade, representa para o intérprete de música erudita a possibilidade de desvendar com expressividade o secreto que habita a obra musical, aquilo que transpassa o universo dos signos gráficos descritos na partitura, aquilo que ainda não foi desvendado, ou que desvendado, assume um novo sentido (Lima, 2006, p. 63). 
Esse argumento não afasta a importância de um relato histórico capaz de demonstrar o quanto as práticas improvisatórias estiveram presentes nos processos de criação composicional e na performance. Ela sempre esteve presente na gênese das novas concepçōes que viriam a se tornar estilos ou na criação de novas modalidades notacionais, contribuindo, mesmo que de forma nebulosa, para o desenvolvimento das mesmas. Entretanto, à medida que esses sistemas notacionais e estilos se consolidavam, a improvisação saía de cena.

A improvisação na música erudita sucumbiu ao tempo, principalmente se considerarmos o peso que a música ocidental erudita atribui à tradição escrita. Encontrar um ponto de equilíbrio entre essa atividade e a sua perpetuidade parece ser a questão fundamental a se trabalhar. Como medida preliminar, acreditamos que a inserção da improvisação na matriz curricular dos cursos técnicos e superiores de instrumento e canto erudito seria um facilitador, trazendo inúmeros benefícios para a performance, a interpretação e a criação musical.

\section{Referências}

BAILEY, Dereck. Improvisation: its nature and practice in music. USA: Da Capo Press, 1993.

BRINGS, Allen; BURKHART, Charles; KAMIEN, Roger; KRAFT, Leo; PERSHING, Drora. A new approach to keybord harmony. New York: W.W. Norton, 1979.

DICIONÁRIO GROVE DE MÚSICA. Edição concisa. Rio de Janeiro: Jorge Zahar, 1994.

DICIONÁRIO OXFORD. New York: Oxford University Press, 1999.

GAINZA, Violeta H. de. La improvisación musical. Buenos Aires: Ricordi, 1983.

GALWAY, James. A música no tempo. São Paulo: Martins Fontes, 1987.

GRIFFITHS, Paul. A música moderna: uma história concisa e ilustrada de Debussy a Boulez. Rio de Janeiro: Jorge Zahar, 1978.

IAZZETA, Fernando. Reflexões sobre a música e o meio. In: XIII ENCONTRO NACIONAL DA ANPPOM, 1., Belo Horizonte, 2001. Anais... Belo Horizonte: Escola de Música da UFMG.

JARINTONSKY, Perla. A muchas preguntas, algunas respuestas. La expresión corporal en el nivel inicial. In: MALAJOVICH. Ana (Compiladora). Recorridos didácticos en la educación inicial. Buenos Aires: Paidós, 2000. p. 91-114.

JARRETT, Keith. The Köl/ Concert. Mainz: Schott, 1991. 1 Partitura. Original transcription: piano. 
LIMA, Sonia Albano de. O virtual e o Real da Interpretação musical. In: (Org). Performance e interpretação musical: uma prática interdisciplinar. São Paulo: Musa, 2006. . Uma metodologia de interpretação musical. São Paulo: Musa, 2005.

LEMOS, Maya Suemy. Do tempo analógico ao tempo abstrato: a música mensurata $e$ a construção da temporalidade moderna. Estudos Históricos, Rio de Janeiro, n. 35, p. 159175, jan.-jun. 2005.

MARTIN, Elisa Ramos. La polifonia al ritmo de Notre Dame: Paris marcando estilo. Disponível em: http://www.filomusica.com/filo22/eli.html. Acesso em: 8 mar. 2009.

MENUHIN, Yehudi; DAVIS, Curt W. A música do homem. São Paulo: Martins Fontes, 1981.

NACHMANOVITCH, Stephen. Ser criativo: o poder da improvisação na vida e na arte. Trad. Eliana Rocha. São Paulo: Summus, 1993.

ROCHA, Fernando Oliveira. A improvisação na música indeterminada; análise de três obras brasileiras para percussão. Dissertação - UFMG, 2001.

SAISSE, Manoel Carlos Pego. Tecnologia e música: os instrumentos eletrônicos e o controle da execução musical. Música Hoje - Revista de Pesquisa Musical, n. 2., p. 41-56, [199-?].

Sonia Albano de Lima: soniaalbano@uol.com.br

Artigo recebido e aprovado em 14 de junho de 2009 